\title{
The Difference of Expression of 18 Genes in Axillary Invasion and Vascular Invasion Compared to Control Samples in Breast Cancer
}

\author{
Alireza Abdollahi' ${ }^{1}$, Sepideh Jahanian ${ }^{2 *}$, Nima Hemmati ${ }^{2}$ iD Hadis Mohammadpour $^{1}$ \\ 1. Department of Pathology, School of Medicine, Tehran University of Medical Sciences, Tehran, Iran \\ 2. Student Research Committee, School of Medicine, Iran University of Medical Sciences, Tehran, Iran
}

\section{KEYWORDS \\ Breast cancer, \\ Gene, \\ Epithelial-mesenchymal transition, \\ Lymphovascular invasion \\ Scan to discover online

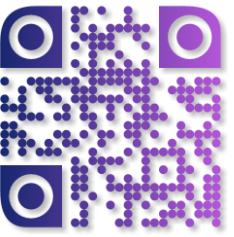

\begin{tabular}{c}
\hline Main Subjects: \\
Breast Pathology \\
\hline Received 23 Aug 2018; \\
Accepted 17 Jun 2019; \\
Published Online 01 Aug 2019; \\
\hline
\end{tabular}

10.30699/ijp.2019.92094.1894

PMCID:

PMID:

\section{ABSTRACT}

Background \& Objective: Recent studies from gene profiling have revealed some genes that are overexpressed in the epithelial-mesenchymal transition (EMT) process and are responsible for its initiation and activation resulting in tumor progression and metastasis. The present study aimed to assess the role of genes involved in the EMT process and the association of these genes with axillary lymph node and vascular invasion in breast cancer (BC) patients.

Methods: In this case-control study, the tumor samples were initially extracted from 33 BC patients. The samples of $15 \mathrm{BC}$ tissues without vascular and axillary invasion were also prepared from the biobank as a control group. RNAs from both tumor and control samples were extracted and stabilized. For assessing overexpression in tumor tissues of selected 18 genes, the real time technique was employed.

Results: There was a significant increase in MMP-2 gene fold expression in tumor cells with vascular invasion regardless of axillary involvement compared to the control group $(P=0.0008)$ and also in the comparison of the control group with those with vascular invasion and not axillary lymph node involvement $(P=0.003)$. In addition, gene fold expression of tissue inhibitors of metalloproteinase-1(TIMP-1) was decreased in axillary involving tumor cells compared to control group $(P=0.045)$, and also in comparison with all samples that did not present any axillary lymph node involvements including the control group and the group with isolated vascular invasion $(P=0.012)$.

Conclusion: Overexpression of MMP-2 and under-expression of TIMP-1 were associated with more invasive behavior in breast tumor cells.

Corresponding Information: Sepideh Jahanian, Student Research Committee, School of Medicine, Iran University of Medical Sciences, Tehran, Iran, Email: sepijah@gmail.com

Copyright @ 2019 . This is an open-access article distributed under the terms of the Creative Commons Attribution- 4.0 International License which permits

Share, copy and redistribution of the material in any medium or format or adapt, remix, transform, and build upon the material for any purpose, even commercially.

\section{Introduction}

Breast cancer $(\mathrm{BC})$ is a common malignant disease among both eastern and western women leading to high mortality rate, disability, and impaired quality of life (1). This malignant disorder has been identified as the second cause of cancer-related deaths followed by lung cancer in women accounting for $23 \%$ of cancer diagnoses (2). Despite a higher incidence of BC among developing countries, more than half of $\mathrm{BC}$ deaths are now thought to occur in the industrialized countries (3). The main etiology for BC mortality is due to the late diagnosis of metastases to distant sites especially to the vital organs; however, recently by applying screening tools, improvement of cancer-related healthcare, and development of adjuvant therapy, the mortality related to BC could be significantly controlled $(4,5)$.

Lymphovascular invasion is a preceding step of metastasis and is considered when the neoplastic cells are seen in lymphatic and blood vessels. As indicated in previous studies, the lymphovascular invasion is related to a poorer survival (6), poorly differentiated tumors, distant metastasis, and recurrence (7), however, the particular molecular mechanism of lymphovascular invasion is not yet fully discovered $(8,9)$.

The distant metastasis of the malignant tumors can be explained by various theories. In epithelial tumors such as breast tumor, the epithelial-mesenchymal transition (EMT) phenomenon can appropriately explain the processes of distant metastasis (10). Recent studies from gene profiling have revealed some genes that can be overexpressed within the EMT process causing its activation and leading to tumor progression and metastasis $(11,12)$. Moreover, the expression of these genes in the EMT process may be associated with other tumor-related behaviors including vascular and lymphatic invasions which play a critical role in planning distant metastasis (13).

Previous studies showed an association of matrix metalloproteinase (MMP) and tissue inhibitors of 
metalloproteinase (TIMP) with metastasis in BC (14). Furthermore, some studies investigated the effect of blocking MMP-2 expression on cancer invasion (15). TIMP-1 seems to be a potential biomarker for diagnosis and prognosis of different malignancies (16).

The present study aimed to assess the profiling of the genes involved in EMT process and its association with axillary lymph node involvement and vascular invasion in $\mathrm{BC}$ patients.

\section{Materials and Methods}

\section{Patients and Sampling}

The tumor samples were extracted from 33 diagnosed BC patients with lymphovascular invasion kept at the Iran Tumor Biobank (Iran Cancer Institute). In addition, 15 control samples were randomly selected from BC tissues without vascular and axillary invasion, also provided from the tumor biobank. Informed consent was obtained from patients before the procedure.

The samples were kept in nitrogen after the surgery and were examined by a pathologist. Extracted RNAs from tumor and control samples were stabilized using the Ribo Ex preservation solution (Geneall, Daejeon, Korea).

\section{RNA extraction}

To extract the RNAs from tissues, $1 \mathrm{~mL}$ Ribo Ex solution was transferred to the tube and then the tissue in the tube was homogenized and centrifuged for 10 seconds. Thereafter, $200 \mu \mathrm{L}$ chloroform was added to the tube and the tube was centrifuged at $1700 \mathrm{~g}$ for 15 minutes. After adding chloroform, the superficial phase including RNAs was transferred into a new tube. Then, $500 \mathrm{~mL}$ isopropanol was poured into the new tube and centrifuged at maximal speed $(14,000 \mathrm{rpm})$ for $20 \mathrm{~min}$. There was a pellet barely visible at the base of each tube. The isopropanol was poured off and added with $1 \mathrm{ml}$ of $75 \%$ ethanol in DEPC treated $\mathrm{H}_{2} \mathrm{O}$ and mixed gently. Then, the ethanol was poured off and let the pellets airdry to store the RNAs. The quantity of RNAs was measured using NanoDrop 2000 Spectrophotometer. Also, the quality of the RNAs was tested by gel electrophoresis. The capacity cDNA reverse transcription kit (TaKaRa Bio Inc., Japan) was used for the quantitative conversion of total RNA to complementary DNA (cDNA). The products were amplified by polymerase chain reaction (PCR) and then were run on the gel. Gene expression was assessed by real time polymerase chain reaction (RT-PCR) using the specific primers. For analysis of the expression of the genes, the $2^{-\Delta \Delta C T}$ method was used. Briefly, the mean target gene mRNA expression level for the mRNA measurements was calculated. The $2^{-\Delta \Delta C T}$ method was used to calculate relative changes in gene expression determined from quantitative RTPCR experiments. The data were presented as the fold change in target gene expression in tumors normalized to the internal control gene $(G A P D H)$ and relative to the control group (matched normal as a calibrator). Results of the RT-PCR data were represented as $\mathrm{C}_{\mathrm{T}}$ values, where $C_{T}$ was defined as the threshold cycle number of PCRs at which amplified product was first detected. There was an inverse correlation between $\mathrm{C}_{\mathrm{T}}$ and amount of the target: lower amounts of the target correspond to a higher $\mathrm{C}_{\mathrm{T}}$ value, and higher amounts of the target have lower $\mathrm{C}_{\mathrm{T}}$ values. The average $\mathrm{C}_{\mathrm{T}}$ was calculated for both the target genes and $G A P D H$, and the $\triangle \mathrm{C}_{\mathrm{T}}$ was determined as (the mean of the triplicate $\mathrm{C}_{\mathrm{T}}$ values for the target gene) minus (the mean of the triplicate $\mathrm{C}_{\mathrm{T}}$ values for $\left.G A P D H\right)$. The $\Delta \Delta \mathrm{C}_{\mathrm{T}}$ represented the difference between the paired tissue samples, as calculated by the formula $\Delta \Delta \mathrm{C}_{\mathrm{T}}=\left(\Delta \mathrm{C}_{\mathrm{T}}\right.$ of tumor $-\Delta \mathrm{C}_{\mathrm{T}}$ of normal $)$. The $\mathrm{N}$-fold differential expression in the target gene of a tumor sample compared to the control sample counterpart was expressed as $2^{-\Delta \Delta C T}(16-18)$.

\section{Statistical Analysis}

To describe quantitative variables, median and range were used and for qualitative variables frequency was used. To analyze the difference of variables a MannWhitney U test was performed. The data were entered and analyzed by SPSS version 17 .

\section{Ethical Considerations}

This study was approved by the ethics committee of the Tehran University of Medical Sciences. Informed consent was obtained from patients before the surgery.

\section{Results}

A total of 48 samples was assessed and analyzed in this study. Among these samples, vascular invasion was seen in $68.75 \%$, in which $43.75 \%$ had isolated vascular invasion and $25 \%$ had axillary lymph node invasion alongside the vascular invasion. Control samples were $31.25 \%$ of total samples. All of the samples with lymph node axillary invasion also had a vascular invasion. Patients' age was lower than 35 years in 14\%, 35 to 50 years in $40 \%$, and higher than 50 years in $46 \%$. Following the Kolmogorov-Smirnov test, the collected data regarding gene fold change were not normally distributed; therefore, we described the median and range for those data. Table (1) illustrates these indices regarding fold changes in different variables.

We used the Mann-Whitney $U$ test for analyzing the data due to the non-normal distribution of our variables. The results of this analysis concerning the difference of gene fold expression in the control group and all patients with vascular invasion regardless of axillary involvement are presented in Table (2). MMP-2 gene fold expression was significantly higher in vascular invasion group (median=657.21) compared to control group $($ median=16.7) $(P=0.008)$.

The results of gene fold expression difference comparing the control group and group with isolated vascular invasion (without axillary invasion) are shown in Table (3). MMP-2 was significantly higher in isolated vascular invasion (median=981.63) compared to control group $($ median=16.7) $(P=0.003)$. 
Table1. Gene fold indices assessed for each variable

\begin{tabular}{|c|c|c|c|c|c|}
\hline & Gene & Median & Minimum & Maximum & Range \\
\hline 1 & TIMP-1 $1^{\mathscr{H}}$ & 61.875 & 0.004 & 1096.59 & 1096.586 \\
\hline 2 & MMP-2 $2^{\star}$ & 256.498 & 0.33 & 54815 & 54814.67 \\
\hline 3 & Claudin & 4.46 & .061 & 13404.3 & 13404.239 \\
\hline 4 & MMP-9^ & 7.035 & 0.003 & 642.9 & 642.897 \\
\hline 5 & MEST $^{\circ}{ }^{\circ}$ & 0.432 & 0.003 & 14022.194 & 14022.191 \\
\hline 6 & Radixin & 1.615 & 0.034 & 19.769 & 19.735 \\
\hline 7 & Cortactin & 226.53 & 0.089 & 62038.073 & 62037.984 \\
\hline 8 & Cofilin & 3.58 & 0.009 & 1802.5 & 1802.491 \\
\hline 9 & $\operatorname{MEST} 2^{\diamond}$ & 0.355 & 0.001 & 45.36 & 45.359 \\
\hline 10 & EOMES $^{\square}$ & 11.198 & 0.2032 & 578.1 & 577.8968 \\
\hline 11 & MEST $^{\circ}$ & 0.223 & 0.002 & 861.085 & 861.083 \\
\hline 12 & Villin & 0.491 & 0.002 & 67.28 & 67.278 \\
\hline 13 & Gelsolin & 7.8 & 0.05 & 11578.09 & 11578.04 \\
\hline 14 & FGF10 ${ }^{\nabla}$ & 0.55 & 0.003 & 69.63 & 69.627 \\
\hline 15 & Fibronectin & 469.81 & 0.098 & 41719.07 & 41718.972 \\
\hline 16 & Vimentin & 88.44 & 0.096 & 1236.69 & 1236.594 \\
\hline 17 & $\mathrm{AXL}$ & 31.81 & 0.25 & 13269.7 & 13269.45 \\
\hline 18 & GAS6 $^{\#}$ & 3.37 & 0.009 & 1802582 & 1802.573 \\
\hline \multicolumn{6}{|c|}{$\begin{array}{l}{ }^{\star} \text { MMP: Matrix metalloproteinase } \\
\text { of TIMP: Tissue inhibitor of metalloproteinase } \\
\text { } \\
\text { } \text { MEST: Mesoderm specific transcript } \\
\text { } \text { EOMES: Eomesodermin } \\
{ }^{\nabla} \text { FGF: Fibroblast growth factor } \\
\text { "GAS: Growth arrest specific }\end{array}$} \\
\hline
\end{tabular}

Table2. Differences of gene fold expression in control group and vascular invasion group including isolated vascular invasion and concurrent vascular and axillary invasion

\begin{tabular}{|c|c|c|c|c|c|}
\hline & Gene & $\begin{array}{l}\text { Mean rank of control group } \\
\mathrm{N}=15\end{array}$ & $\begin{array}{l}\text { Mean rank of vascular invasion group } \\
\qquad \mathbf{N}=33\end{array}$ & M-U* & P-value \\
\hline 1 & TIMP-1भ & 27.27 & 23.24 & 206 & 0.356 \\
\hline 2 & ${\mathrm{MMP}-2^{\star}}^{\star}$ & 16.2 & 27.66 & 123 & 0.008 \\
\hline 3 & Claudin & 20.32 & 24.89 & 179.5 & 0.288 \\
\hline 4 & MMP-9 ${ }^{\star}$ & 18.57 & 24.33 & 155 & 0.166 \\
\hline 5 & MEST1 $^{\circ}$ & 26.21 & 21.55 & 172 & 0.270 \\
\hline 6 & Radixin & 21.62 & 24.24 & 190 & 0.550 \\
\hline 7 & Cortactin & 25.21 & 22.75 & 200 & 0.567 \\
\hline 8 & Cofilin & 22.14 & 24.79 & 205 & 0.545 \\
\hline 9 & $\operatorname{MEST} 2^{\diamond}$ & 23.20 & 23.65 & 228 & 0.916 \\
\hline 10 & EOMES $^{\square}$ & 21.57 & 23.65 & 197 & 0.624 \\
\hline 11 & MEST3 $^{\circ}$ & 19.25 & 23.72 & 153 & 0.304 \\
\hline 12 & Villin & 25.00 & 22.84 & 203 & 0.616 \\
\hline 13 & Gelsolin & 21.64 & 2217 & 198 & 0.897 \\
\hline 14 & FGF10 ${ }^{\nabla}$ & 22.43 & 23.97 & 209 & 0.720 \\
\hline 15 & Fibronectin & 23.27 & 24.34 & 229 & 0.802 \\
\hline 16 & Vimentin & 22.27 & 23.37 & 214 & 0.791 \\
\hline 17 & AXL & 22.33 & 23.33 & 215 & 0.810 \\
\hline 18 & GAS6 ${ }^{\#}$ & 20.21 & 25.61 & 178 & 0.218 \\
\hline $\begin{array}{l}{ }^{*} \mathrm{M}-\mathrm{U}: \\
{ }^{*} \mathrm{MMF} \\
{ }^{\circ} \mathrm{TIM} \\
{ }^{\circ} \mathrm{MES} \\
\end{array}$ & $\begin{array}{l}\text { Whitney U Index } \\
\text { x metalloproteina } \\
\text { e inhibitor of met } \\
\text { derm specific trat }\end{array}$ & $\begin{array}{l}\text { roteinase; } \\
\mathrm{t} ;{ }^{\square} \mathrm{EOMES}: \text { Eomesodermin; }{ }^{\nabla} \mathrm{FG}\end{array}$ & 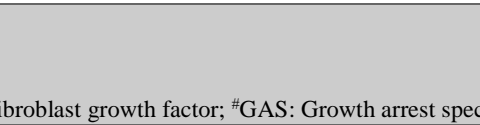 & & \\
\hline
\end{tabular}


Table3. Differences of gene fold expression in control group and vascular invasion group including only isolated vascular invasion cases

\begin{tabular}{|c|c|c|c|c|c|}
\hline & Gene & $\begin{array}{l}\text { Mean rank of control group } \\
\qquad \mathrm{N}=15\end{array}$ & $\begin{array}{l}\text { Mean rank of isolated vascular invasion group } \\
\qquad \mathrm{N}=21\end{array}$ & M-U* & P-Value \\
\hline 1 & TIMP-1 1 H & 18.53 & 18.48 & 157 & 0.987 \\
\hline 2 & ${\mathrm{MMP}-2^{\star}}^{\star}$ & 12.07 & 22.45 & 61 & 0.003 \\
\hline 3 & Claudin & 14.54 & 19.58 & 98.5 & 0.146 \\
\hline 4 & MMP-9^ & 13.50 & 19.58 & 84 & 0.074 \\
\hline 5 & MEST $^{\circ}$ & 19.36 & 17.10 & 128 & 0.522 \\
\hline 6 & Radixin & 15.46 & 18.76 & 110 & 0.348 \\
\hline 7 & Cortactin & 18.36 & 17.76 & 142 & 0.866 \\
\hline 8 & Cofilin & 16.07 & 1929 & 120 & 0.363 \\
\hline 9 & MEST2 $^{\diamond}$ & 18.37 & 17.73 & 144.5 & 0.855 \\
\hline 10 & EOMES $^{\square}$ & 15.50 & 18.90 & 112 & 0.327 \\
\hline 11 & MEST $^{\circ}$ & 13.96 & 18.03 & 89.5 & 0.235 \\
\hline 12 & Villin & 18.50 & 16.80 & 126 & 0.624 \\
\hline 13 & Gelsolin & 16.79 & 18.00 & 130 & 0.726 \\
\hline 14 & FGF10 & 17.29 & 18.48 & 137 & 0.736 \\
\hline 15 & Fibronectin & 17.40 & 19.29 & 141 & 0.596 \\
\hline 16 & Vimentin & 15.87 & 18.79 & 118 & 0.395 \\
\hline 17 & AXL & 16.60 & 18.21 & 129 & 0.640 \\
\hline 18 & GAS6 $^{\#}$ & 14.86 & 20.10 & 103 & 0.138 \\
\hline $\begin{array}{l}{ }^{*} \mathrm{M}- \\
{ }^{\star} \mathrm{MI} \\
{ }^{*} \mathrm{TI} \\
{ }^{\circ} \mathrm{ME} \\
{ }^{\mathrm{E}} \mathrm{EO} \\
{ }^{\mathrm{F}} \mathrm{FG} \\
{ }^{\circ} \mathrm{GA}\end{array}$ & $\begin{array}{l}\text { Inn-Whitney U I } \\
\text { atrix metallopro } \\
\text { issue inhibitor o } \\
\text { lesoderm specifi } \\
\text { Eomesodermin } \\
\text { roblast growth f } \\
\text { wth arrest speci }\end{array}$ & $\begin{array}{l}\text { dex } \\
\text { einase } \\
\text { metalloproteinase } \\
\text { transcript } \\
\text { ictor } \\
\text { fic }\end{array}$ & & & \\
\hline
\end{tabular}

Table (4) demonstrates the difference of gene fold expression between the group with axillary lymph node invasion and groups without axillary lymph node invasion (including controls and those with exclusive vascular invasion). TIMP-1 was significantly lower in axillary invasion group (median=7.78) compared to controls and vascular invasion groups combined (median=90.44) $(P=0.012)$.

Table 4. Gene fold expression differences in groups without axillary lymph node invasion and groups with axillary lymph node invasion

\begin{tabular}{|c|c|c|c|c|c|}
\hline & Gene & $\begin{array}{c}\text { Mean rank of control group and isolated } \\
\text { vascular invasion group } \\
\mathrm{N}=36\end{array}$ & $\begin{array}{l}\text { Mean rank of group with axillary } \\
\text { lymph node invasion } \\
\mathrm{N}=12\end{array}$ & $\mathbf{M}-\mathbf{U}^{*}$ & P-Value \\
\hline 1 & TIMP-1म्8 & 27.42 & 15.75 & 111 & 0.012 \\
\hline 2 & MMP-2 ${ }^{\star}$ & 24.34 & 23.00 & 198 & 0.770 \\
\hline 3 & Claudin & 24.47 & 20.75 & 171 & 0.409 \\
\hline 4 & MMP-9* & 23.33 & 20.00 & 154 & 0.456 \\
\hline 5 & MEST1 $^{\diamond}$ & 24.54 & 17.60 & 121 & 0.140 \\
\hline 6 & Radixin & 24.06 & 21.92 & 185 & 0.635 \\
\hline 7 & Cortactin & 24.80 & 19.36 & 147 & 0.241 \\
\hline 8 & Cofilin & 25.49 & 19.67 & 158 & 0.205 \\
\hline 9 & $\operatorname{MEST}^{\diamond}$ & 22.59 & 26.41 & 160.5 & 0.410 \\
\hline 10 & EOMES $^{\square}$ & 23.97 & 20.00 & 154 & 0.383 \\
\hline 11 & MEST3 $^{\circ}$ & 22.19 & 23.33 & 182 & 0.792 \\
\hline
\end{tabular}

The difference of the gene fold expression in the group with axillary invasion and control group is presented in Table (5). TIMP-1 was significantly lower in axillary invasion group (median=7.78) compared to controls (median=16.7) $(P=0.045)$. 


\begin{tabular}{|c|c|c|c|c|c|}
\hline & Gene & $\begin{array}{c}\text { Mean rank of control group and isolated } \\
\text { vascular invasion group } \\
\mathrm{N}=36\end{array}$ & $\begin{array}{c}\text { Mean rank of group with axillary } \\
\text { lymph node invasion } \\
\mathrm{N}=12\end{array}$ & $\mathbf{M}-\mathbf{U}^{*}$ & P-Value \\
\hline 12 & Villin & 23.99 & 22.13 & 187.5 & 0.680 \\
\hline 13 & Gelsolin & 22.65 & 19.56 & 131 & 0.511 \\
\hline 14 & FGF10 $\nabla$ & 23.04 & 24.95 & 176.5 & 0.680 \\
\hline 15 & Fibronectin & 24.72 & 21.64 & 172 & 0.514 \\
\hline 16 & Vimentin & 24.41 & 18.64 & 139 & 0.205 \\
\hline 17 & AXL & 23.59 & 21.18 & 167 & 0.597 \\
\hline 18 & GAS6 $^{\#}$ & 25.31 & 20.17 & 164 & 0.262 \\
\hline \multicolumn{6}{|c|}{$\begin{array}{l}\text { *M-U: Mann-Whitney U Index } \\
{ }^{\star} \text { MMP: Matrix metalloproteinase } \\
\text { OBTIMP: Tissue inhibitor of metalloproteinase } \\
{ }^{\circ} \text { MEST: Mesoderm specific transcript } \\
\text { 口EOMES: Eomesodermin; } \\
{ }^{\circ} \text { FGF: Fibroblast growth factor } \\
\text { "GAS: Growth arrest specific }\end{array}$} \\
\hline
\end{tabular}

Table 5. Gene fold changes differences in control group and axillary invasion group

\begin{tabular}{|c|c|c|c|c|c|}
\hline & Gene & $\begin{array}{c}\text { Mean rank of control group } \\
\mathrm{N}=\mathbf{1 5}\end{array}$ & $\begin{array}{l}\text { Mean rank of axillary invasion group } \\
\mathrm{N}=12\end{array}$ & $\mathbf{M}-\mathbf{U}^{*}$ & P-Value \\
\hline 1 & TIMP-1 $1^{\mathscr{B}}$ & 16.73 & 10.58 & 49 & 0.045 \\
\hline 2 & MMP-2 $2^{\star}$ & 12.13 & 16.33 & 62 & 0.172 \\
\hline 3 & Claudin & 13.29 & 13.75 & 81 & 0.877 \\
\hline 4 & MMP-9 $9^{\star}$ & 12.57 & 13.55 & 71 & 0.743 \\
\hline 5 & MEST $^{\diamond}$ & 14.36 & 9.90 & 44 & 0.128 \\
\hline 6 & Radixin & 13.15 & 12.83 & 76 & 0.913 \\
\hline 7 & Cortactin & 14.36 & 11.27 & 58 & 0.298 \\
\hline 8 & Cofilin & 13.57 & 13.42 & 83 & 0.959 \\
\hline 9 & $\operatorname{MEST}^{\circ}$ & 12.83 & 14.41 & 75.5 & 0.604 \\
\hline 10 & EOMES $^{\square}$ & 13.57 & 12.27 & 69 & 0.661 \\
\hline 11 & MEST $^{\circ}$ & 11.79 & 13.21 & 63.5 & 0.624 \\
\hline 12 & Villin & 14.00 & 12.92 & 77 & 0.719 \\
\hline 13 & Gelsolin & 12.36 & 11.44 & 58 & 0.753 \\
\hline 14 & FGF10 ${ }^{\nabla}$ & 12.64 & 13.45 & 72 & 0.784 \\
\hline 15 & Fibronectin & 13.87 & 13.00 & 77 & 0.775 \\
\hline 16 & Vimentin & 14.40 & 12.27 & 69 & 0.484 \\
\hline 17 & AXL & 13.73 & 13.18 & 79 & 0.856 \\
\hline 18 & GAS6" & 12.86 & 14.25 & 75 & 0.643 \\
\hline
\end{tabular}

\section{Discussion}

According to the present study, there was a significant increase in MMP-2 gene fold expression in tumor cells with vascular invasion compared to control samples. This was significant comparing the control group with all the samples with vascular invasion regardless of axillary lymph node involvement $(P=0.0008)$ and vascular invasion without axillary lymph node involvement $(P=0.003)$.

Furthermore, it was observed that in tumor cells with axillary lymph node invasion, tissue inhibitors of metalloproteinase-1 (TIMP-1) gene fold expression was lower compared to the control group $(P=0.045)$.
These tumor cells also demonstrated lower increase in TIMP-1 gene fold expression levels when compared to the groups without axillary lymph node involvement including the control group and the group with isolated vascular invasion $(P=0.012)$.

The MMPs are known to have a role in extracellular matrix degeneration (17) and so can contribute to the mechanism on tumor invasion. They are found in both normal cells and neoplastic cells (18) and therefore play a role in some other cell functions such as wound healing, angiogenesis, apoptosis, and immune response as well as tumor invasion (17). 
On the other hand, TIMPs are proteins that can bind to MMPs and inhibit their action (19). TIMP-1, which was assessed in the present study, is known to inhibit MMP-9 whereas MMP-2 is inhibited by TIMP-2 (20). So far, various studies have demonstrated the role of MMPs and their inhibitors including TIMPs in cancer progression and metastasis.

According to a study by Pellikainen et al. in 2004 (17), the expression levels of MMP-2 and MMP-9 were both increased in the cells of breast tumors. However, we did not find a significant increase in MMP09 gene fold expression between groups with invasion and control group in the present study. Although the difference of MMP-9 expression was not significant in our study, the results of previous studies regarding MMP-2 are in accordance with those of the current study. This could be justified by the difference of methods used to measure the expressions of genes, since in this study the researchers used RT-PCR method and quantitative measurements of gene expressions but in the study by Pellikainen et al., the differences of expressions were measured by categorical analysis with a cut-off point of $80 \%$ for MMP-2 and $85 \%$ for MMP-9 of cytoplasmic expressions in immunohistochemistry test. Although the expression of MMP-9 increased in the vascular invasion in this study, the difference was not significant.

The study by Figueira et al. (2009) showed higher amounts of MMP-2, MMP-9, TIMP-1, and TIMP-2, and reversion inducing cysteine-rich protein (RECK) levels in more aggressive cells compared to the less aggressive cancer cells (21). In our study, the amounts of TIMP-1 were significantly lower in patients with axillary lymph node invasion compared to control samples. But as it was noted before, the amounts of MMP-2 increased in samples with vascular invasion and groups with axillary and vascular invasion compared to the control group. This might be explained by the fact that the grouping method was different in the study by Figueira et al. and the current research; while they based their grouping on the cell line of malignant cells and the histopathology, we based it on axillary invasion, vascular invasion, and controls. Although both studies showed that all of the mentioned genes increase proportional to normal expressions, it seems that the findings of the study by Figueira et al. regarding TIMP-1 gene cannot be completely true due to the lack of controls in their study.

Owing to the fact that the present study aimed to assess the genes that might be involved in the invasive behavior of BC cells through utilizing the EMT process, some of the studies that have discovered the association between these genes and lymph node invasion in cancers other than breast are discussed below; these findings support the key role of MMP and TIMP genes in the process of metastasis.

In a study conducted by Yao et al. (2017), high amounts of MMP-2 and MMP-9 in early gastric cancer cells were significantly associated with lymph node metastasis and ulceration. The mentioned study also showed that the prognostic value of MMP-2/MMP-9 overexpression was independent of other tumor prognostic factors like tumor size, depth, and the number of lymph nodes involved in lymph node metastasis (22). Another study by Wang et al. (2011) suggested that upregulation of platelet-derived growth factor-D enhances the expression of MMP-2 and MMP-9 contributing to the invasion of ovarian tumor cells (23). Huang et al. (2013) also found a significant difference of MMP-2 expressions in lymph node metastatic cells of the patients with nasopharyngeal cancer metastasized to cervical lymph nodes (24). Among head and neck cancers, a study by Zhou et al. (2010) showed an association between MMP-2 and MMP-9 overexpression in cervical lymph node metastasized tongue cancers (25).

Considering the $\mathrm{BCs}$, the existing evidence supports the overexpression of MMP-2 gene and invasive behavior (26-28), which is in line with the findings of our study.

Despite the known role of TIMP-1 as being MMP inhibitors, it seems that the function of this protein is more complicated as some studies have shown that high TIMP levels tend toward cancer progression.

A study by D'Angelo et al. (2014) found a significant association between TIMP-1 overexpression and EMTlike conversions such as phenotypic changes of vascular cells leading to adhesion molecule loss (29), which can explain the beginning of invasion as described in the EMT process theories.

The study of Clarke and et al. (2015) showed that the inhibitions of TIMP-1 and -2 are responsible for the invasion of BC cells, probably due to their inhibitory effects on MMPs (16). Meanwhile, our study revealed that the relative decrease of TIMP-1 in comparison to control group was associated with the invasive behavior of the tumor. In a study by Bernert et al. (2011), the induction of TIMP-1 resulted in the invasive capability of BC cells by suppressing the hyaluronan synthase 2 (30).

In another study related to colorectal cancer by Song et al. (2016), the human cancer cells showed a significant increase in TIMP-1 levels compared to controls. In addition, the lymph node-positive patients showed a significantly higher amount of TIMP-1, which proves its role in invasion and metastasis (31).

In contrast to many studies showing high TIMP-2 expression in neoplastic cells with lymph node invasions, a study by Iniesta P. et al. (2007) confirmed a decrease in TIMP-2 measurements along with increased MMP-2 levels concurrently in non-small-cell lung carcinoma (NSCLC) patients (32). Interestingly, TIMP2 , regardless of its name, increased MMP-2 levels in animal experiments (29).

The association of TIMPs with the progression of cancer seems to be due to other functions of these molecules. TIMP-1 promotes angiogenesis by upregulating vascular endothelial growth factor and inhibits apoptosis. TIMP-2 also inhibits apoptosis and promotes neoplastic growth (33-35). It has been 
suggested that the integrity of the cellular matrix is preserved when the MMP/TIMP levels are balanced (36).

A study by Valente et al. (1998) on melanoma cells confirmed the overexpression of TIMP-2 cells, which was also associated with less migration and endothelial invasion compared to control cells (37).

In a study by Batra et al. (2012), cancer cell invasion and tumor gelatinase (MMPs) activity was inhibited by PEGylating (conjugating with polyethylene glycol) recombinant human TIMP-1 (38). This could be an emphasis on the inhibitory role of TIMPs.

Ikenaka et al. (2003) observed that the amounts of MMP-2 and MMP-9 decreased in the tumor cells of transgenic mice following ectopic TIMP-1 due to its inhibitory effect on cell growth and angiogenesis (39).

As mentioned before and in contrast to most studies, the present study found lower levels of TIMP-1 in samples with axillary invasion compared to control group and vascular invasion group without axillary lymph node involvement. This finding could be explained by the findings of various studies regarding TIMPs. For example, a study of pancreatic tumor cells by Rigg et al. (2001) showed that although TIMP-1 levels are overexpressed in malignant cells, it appears that these proteins change the tumor invasive behavior as it reduces tumor cells reaching out to distant organs (40).

The sample size of this study was limited and data were not normally distributed. Therefore, we suggest designing a study with larger sample size and normal distribution. Unfortunately, the authors cannot calculate the minimum sample size required for future studies but we recommend other researchers to choose complete datasets. It should also be noted that the researchers did not consider distant metastasis in the present study. So, a complementary study to investigate this variable can be helpful.

\section{Conclusion}

In conclusion, the present study demonstrated that cells with more invasive behavior express higher MMP-2 and lower TIMP-1 levels. However, the prognostic value of these molecules is not fully understood. As the role of these molecules in the process of invasion and tumor progression becomes clearer, more direct studies can be conducted to use them as target therapies or markers in the future.

\section{Acknowledgements}

This research received no specific grant from any funding agency in the public, commercial, or not-forprofit sectors.

\section{Conflict of Interest}

The authors declare that there is no conflict of interest regarding the publication of this article.

\section{References}

1. Altobelli E, Rapacchietta L, Angeletti PM, Barbante L, Profeta FV, Fagnano R. Breast Cancer Screening Programmes across the WHO European Region: Differences among Countries Based on National Income Level. International journal of environmental research and public health. 2017;14(4). [DOI:10.3390/ijerph14040452] [PMID] [PMCID]

2. Reeder-Hayes KE, Anderson BO. Breast Cancer Disparities at Home and Abroad: A Review of the Challenges and Opportunities for System-Level Change. Clinical cancer research : an official journal of the American Association for Cancer Research. 2017;23(11):2655-64. [DOI:10.1158/1078-0432.CCR-162630] [PMID] [PMCID]

3. Olver I. Cancer control-A global perspective. European journal of cancer care. 2017;26(1). [DOI:10.1111/ecc.12654] [PMID]

4. Moon Z, Moss-Morris R, Hunter MS, Carlisle S, Hughes LD. Barriers and facilitators of adjuvant hormone therapy adherence and persistence in women with breast cancer: a systematic review. Patient Prefer Adherence. 2017;11:30522. [DOI:10.2147/PPA.S126651] [PMID] [PMCID]

5. Pan R, Zhu M, Yu C, Lv J, Guo Y, Bian Z, Yang L, Chen Y, Hu Z, Chen Z, Li L. Cancer incidence and mortality: A cohort study in China, 2008-2013. International journal of cancer. $2017 \quad$ Oct $1 ; 141(7): 1315-23$. [DOI:10.1002/ijc.30825] [PMID]

6. Gujam FJ, Going JJ, Edwards J, Mohammed ZM, McMillan DC. The role of lymphatic and blood vessel invasion in predicting survival and methods of detection in patients with primary operable breast cancer. Critical reviews in oncology/hematology. 2014;89(2):231-41. [DOI:10.1016/j.critrevonc.2013.08.014] [PMID]

7. Mohammed RA, Martin SG, Mahmmod AM, Macmillan RD, Green AR, Paish EC, et al. Objective assessment of lymphatic and blood vascular invasion in lymph nodenegative breast carcinoma: findings from a large case series with long-term follow-up. The Journal of pathology. 2011;223(3):358-65. [DOI:10.1002/path.2810] [PMID]

8. Klahan S, Wong HS, Tu SH, Chou WH, Zhang YF, Ho $\mathrm{TF}$, et al. Identification of genes and pathways related to lymphovascular invasion in breast cancer patients: A bioinformatics analysis of gene expression profiles. Tumour biology : the journal of the International Society for Oncodevelopmental Biology and Medicine. 2017;39(6): 1010428317705573. [DOI:10.1177/1010428317705573] [PMID]

9. Aleskandarany MA, Sonbul SN, Mukherjee A, Rakha EA. Molecular Mechanisms Underlying Lymphovascular Invasion in Invasive Breast Cancer. Pathobiology. 2015;82(3-4):113-23. [DOI:10.1159/000433583] [PMID]

10. Karlsson MC, Gonzalez SF, Welin J, Fuxe J. Epithelialmesenchymal transition in cancer metastasis through the lymphatic system. Molecular oncology. 2017;11(7):78191. [DOI:10.1002/1878-0261.12092] [PMID] [PMCID]

11. Szynglarewicz B, Kasprzak P, Donizy P, Biecek P, Halon A, Matkowski R. Epithelial-mesenchymal transition inducer Snail1 and invasive potential of intraductal breast cancer. Journal of surgical oncology. 2017;116(6):696705. [DOI:10.1002/jso.24708] [PMID] 
12. Lakhtakia R, Aljarrah A, Furrukh M, Ganguly SS Epithelial Mesenchymal Transition (EMT) in Metastatic Breast Cancer in Omani Women. Cancer microenvironment : official journal of the International Cancer Microenvironment Society. 2017;10(1-3):25-37. [DOI:10.1007/s12307-017-0194-9] [PMID] [PMCID]

13. Chui MH. Insights into cancer metastasis from a clinicopathologic perspective: Epithelial-Mesenchymal Transition is not a necessary step. Int $\mathbf{J}$ Cancer. 2013;132(7):1487-95. [DOI:10.1002/ijc.27745] [PMID]

14. Li H, Qiu Z, Li F, Wang C. The relationship between MMP-2 and MMP-9 expression levels with breast cancer incidence and prognosis. Oncology letters. 2017;14(5):5865-70. [DOI:10.3892/ol.2017.6924] [PMID] [PMCID]

15. Kang DY, Sp N, Kim DH, Joung YH, Lee HG, Park YM, et al. Salidroside inhibits migration, invasion and angiogenesis of MDAMB 231 TNBC cells by regulating EGFR/Jak2/STAT3 signaling via MMP2. International journal of oncology. 2018;53(2):877-85. [DOI:10.3892/ijo.2018.4430]

16. Clarke MR, Imhoff FM, Baird SK. Mesenchymal stem cells inhibit breast cancer cell migration and invasion through secretion of tissue inhibitor of metalloproteinase1 and-2. Molecular carcinogenesis. 2015 Oct;54(10):12149. [DOI:10.1002/mc.22178] [PMID]

17. Pellikainen JM, Ropponen KM, Kataja VV, Kellokoski JK, Eskelinen MJ, Kosma VM. Expression of matrix metalloproteinase (MMP)-2 and MMP-9 in breast cancer with a special reference to activator protein-2, HER2, and prognosis. Clinical cancer research : an official journal of the American Association for Cancer Research. 2004;10(22):7621-8. [DOI:10.1158/1078-0432.CCR-041061] [PMID]

18. Bjorklund M, Koivunen E. Gelatinase-mediated migration and invasion of cancer cells. Biochim Biophys Acta. 2005;1755(1):37-69. [DOI:10.1016/j.bbcan.2005.03.001] [PMID]

19. Egeblad M, Werb Z. New functions for the matrix metalloproteinases in cancer progression. Nat Rev Cancer. 2002;2(3):161-74. [DOI:10.1038/nrc745] [PMID]

20. O'Connell JP, Willenbrock F, Docherty AJ, Eaton D, Murphy G. Analysis of the role of the $\mathrm{COOH}$-terminal domain in the activation, proteolytic activity, and tissue inhibitor of metalloproteinase interactions of gelatinase B. J Biol Chem. 1994;269(21):14967-73.

21. Figueira RC, Gomes LR, Neto JS, Silva FC, Silva ID, Sogayar MC. Correlation between MMPs and their inhibitors in breast cancer tumor tissue specimens and in cell lines with different metastatic potential. BMC Cancer. 2009;9:20. [DOI:10.1186/1471-2407-9-20] [PMID] [PMCID]

22. Yao Z, Yuan T, Wang H, Yao S, Zhao Y, Liu Y, et al. MMP-2 together with MMP-9 overexpression correlated with lymph node metastasis and poor prognosis in early gastric carcinoma. Tumour biology : the journal of the International Society for Oncodevelopmental Biology and Medicine. 2017;39(6):1010428317700411. [DOI:10.1177/1010428317700411] [PMID]

23. Wang Y, Hu C, Dong R, Huang X, Qiu H. Platelet-derived growth factor-D promotes ovarian cancer invasion by regulating matrix metalloproteinases 2 and 9. Asian Pac J Cancer Prev. 2011;12(12):3367-70.
24. Huang $\mathrm{T}$, Chen $\mathrm{MH}$, Wu MY, Wu XY. Correlation between expression of extracellular matrix metalloproteinase inducer and matrix metalloproteinase-2 and cervical lymph node metastasis of nasopharyngeal carcinoma. Ann Otol Rhinol Laryngol. 2013;122(3):2105. [DOI:10.1177/000348941312200311] [PMID]

25. Zhou CX, Gao Y, Johnson NW, Gao J. Immunoexpression of matrix metalloproteinase-2 and matrix metalloproteinase- 9 in the metastasis of squamous cell carcinoma of the human tongue. Aust Dent J. 2010;55(4):385-9. 7819.2010.01258.x] [PMID]

26. Zhang S, Ma J, Fu Z, Zhang Z, Cao J, Huang L, et al. Promotion of breast cancer cells MDA-MB-231 invasion by di(2-ethylhexyl)phthalate through matrix metalloproteinase-2/-9 overexpression. Environmental science and pollution research international. 2016;23(10):9742-9. [DOI:10.1007/s11356-016-6158-7] [PMID]

27. Cui HX, Wang H, Wang Y, Song J, Tian H, Xia C, et al. ST3Gal III modulates breast cancer cell adhesion and invasion by altering the expression of invasion-related molecules. Oncology reports. 2016;36(6):3317-24. [DOI:10.3892/or.2016.5180] [PMID]

28. Jiang Q, Pan Y, Cheng Y, Li H, Liu D, Li H. Lunasin suppresses the migration and invasion of breast cancer cells by inhibiting matrix metalloproteinase-2/-9 via the FAK/Akt/ERK and NF-kappaB signaling pathways. Oncology reports. 2016;36(1):253-62. [DOI:10.3892/or.2016.4798] [PMID]

29. D'Angelo RC, Liu XW, Najy AJ, Jung YS, Won J, Chai $\mathrm{KX}$, et al. TIMP-1 via TWIST1 induces EMT phenotypes in human breast epithelial cells. Mol Cancer Res. 2014;12(9):1324-33. [DOI:10.1158/1541-7786.MCR-140105] [PMID] [PMCID]

30. Bernert B, Porsch H, Heldin P. Hyaluronan synthase 2 (HAS2) promotes breast cancer cell invasion by suppression of tissue metalloproteinase inhibitor 1 (TIMP1). J Biol Chem. 2011;286(49):42349-59. [DOI:10.1074/jbc.M111.278598] [PMID] [PMCID]

31. Song G, Xu S, Zhang H, Wang Y, Xiao C, Jiang T, et al. TIMP1 is a prognostic marker for the progression and metastasis of colon cancer through FAK-PI3K/AKT and MAPK pathway. J Exp Clin Cancer Res. 2016;35(1):148. [DOI:10.1186/s13046-016-0427-7] [PMID] [PMCID]

32. Iniesta $\mathrm{P}$, Moran A, De Juan C, Gomez A, Hernando F, Garcia-Aranda C, et al. Biological and clinical significance of MMP-2, MMP-9, TIMP-1 and TIMP-2 in non-small cell lung cancer. Oncology reports. 2007;17(1):217-23. [DOI:10.3892/or.17.1.217] [PMID]

33. Hayakawa T, Yamashita K, Ohuchi E, Shinagawa A. Cell growth-promoting activity of tissue inhibitor of metalloproteinases-2 (TIMP-2). J Cell Sci. 1994;107 ( Pt 9):2373-9

34. Bertaux B, Hornebeck W, Eisen AZ, Dubertret L. Growth stimulation of human keratinocytes by tissue inhibitor of metalloproteinases. J Invest Dermatol. 1991;97(4):679-85. [DOI:10.1111/1523-1747.ep12483956] [PMID]

35. Murphy AN, Unsworth EJ, Stetler-Stevenson WG. Tissue inhibitor of metalloproteinases-2 inhibits bFGF-induced human microvascular endothelial cell proliferation. J Cell Physiol. https://doi.org/10.1002/jcp.1041210212 [DOI:10.1002/jep.1041570219] 
36. Tyagi SC, Kumar SG, Haas SJ, Reddy HK, Voelker DJ, Hayden MR, et al. Post-transcriptional regulation of extracellular matrix metalloproteinase in human heart endstage failure secondary to ischemic cardiomyopathy. J Mol Cell Cardiol 1996;28(7):1415-28 [DOI:10.1006/jmcc.1996.0132] [PMID]

37. Valente P, Fassina G, Melchiori A, Masiello L, Cilli M, Vacca A, et al. TIMP-2 over-expression reduces invasion and angiogenesis and protects $\mathrm{B} 16 \mathrm{~F} 10$ melanoma cells from apoptosis. Int J Cancer. 1998;75(2):246-53. https://doi.org/10.1002/(SICI)1097-

0215(19980119)75:2<246::AID-IJC13>3.0.CO;2-B [DOI:10.1002/(SICI) 1097-0215(19980119)75:23.0.CO;2B]
38. Batra J, Robinson J, Mehner C, Hockla A, Miller E, Radisky DC, et al. PEGylation extends circulation half-life while preserving in vitro and in vivo activity of tissue inhibitor of metalloproteinases-1 (TIMP-1). PLoS One. 2012;7(11):e50028. [DOI:10.1371/journal.pone.0050028] [PMID] [PMCID]

39. Ikenaka Y, Yoshiji H, Kuriyama S, Yoshii J, Noguchi R, Tsujinoue $\mathrm{H}$, et al. Tissue inhibitor of metalloproteinases1 (TIMP-1) inhibits tumor growth and angiogenesis in the TIMP-1 transgenic mouse model. Int $\mathbf{J}$ Cancer. 2003;105(3):340-6. [DOI:10.1002/ijc.11094] [PMID]

40. Rigg AS, Lemoine NR. Adenoviral delivery of TIMP1 or TIMP2 can modify the invasive behavior of pancreatic cancer and can have a significant antitumor effect in vivo. Cancer gene therapy. 2001 Nov;8(11):869. [DOI:10.1038/sj.cgt.7700387] [PMID]

Abdollahi, A., Jahanian, S., Hemmati, N., Mohammadpour, H. The Difference of Expression of 18 Genes in Axillary Invasion and Vascular Invasion Compared to Control Samples in Breast Cancer. Iranian Journal of Pathology, 2019; (): 223-231. doi: 10.30699/ijp.2019.92094.1894 